\title{
Inner Anti-inflammatory Mechanisms of Petroleum Ether Extract from Melilotus suaveolens Ledeb
}

\author{
Lei Zhao, ${ }^{1}$ Jun-Yan Tao, ${ }^{2}$ Shu-Ling Zhang, ${ }^{1}$ Ran Pang, ${ }^{1}$ Feng Jin, ${ }^{3}$ Ji-Hua Dong, \\ and Yuan-Jin Guo ${ }^{5}$
}

\begin{abstract}
Summary. Melilotus suaveolens Ledeb is a species of traditional medical plant for treating inflammationrelated disease. This study is to explore the inner anti-inflammatory mechanism on petroleum ether extract from Melilotus suaveolens Ledeb.

Materials and Methods. Inflammatory cellular model was founded by intervention of lipopolysaccharide (LPS) on RAW264.7 cell line. Secretion of TNF- $\alpha$, IL-1 $\beta$, IL-6, NO and IL-10 in supernatant, mRNA expression of TNF- $\alpha$, COX-2, iNOS and HO-1, protein expression of COX-2 and HO-1, activation of NF$\mathrm{\kappa B}$ and ingredients in the extract were assayed.

Results. The extract could not only reduce production of pro-inflammatory mediators by blocking NF- $\mathrm{\kappa B}$ activation but promote release of anti-inflammatory mediator HO-1 significantly. The only active ingredient in the extract was coumarin and the concentration of coumarin in each $1 \mathrm{~g}$ extract was $0.27822 \mathrm{mg}$. Conclusion. Compared to Dexamethasone, the extract not only has similar effects on antagonizing proinflammatory mediators and cytokines but has effects on promoting production of anti-inflammatory mediators.
\end{abstract}

KEY WORDS: Melilotus suaveolens Ledeb; petroleum ether extract; RAW 264.7 cell line; NF-kappaB; HO-1.

\section{INTRODUCTION}

Melilotus has long been prescribed in traditional medicine for the treatment of inflammation-related diseases [1]. In previous literatures, it was studied that

Lei Zhao and Jun-Yan Tao have equally contributed to this work

${ }^{1}$ To whom correspondence should be addressed at Department of Hepatology and Infectious Disease, Union Hospital, Tongji Medical College, Huazhong University of Science and Technology, Wuhan, 430022, People's Republic of China. E-mail: baihuasheshecao@ 163.com

${ }^{2}$ College of Life Science and Technology, Huazhong University of Science and Technology, Wuhan, 430072, People's Republic of China.

${ }^{3}$ Department of Neurosurgery, Union Hospital, Tongji Medical College, Huazhong University of Science and Technology, Wuhan, 430022, People's Republic of China.

${ }^{4}$ Central Lab, Union Hospital, Tongji Medical College, Huazhong University of Science and Technology, Wuhan, 430022, People's Republic of China.

${ }^{5}$ Department of Neurology, Union Hospital, Tongji Medical College, Huazhong University of Science and Technology, Wuhan, 430022, People's Republic of China. the anti-inflammatory properties of the extract from Melilotus officinalis were similar to those of hydrocortisone sodium hemisuccinate and coumarin, and in bone marrow acute phase response, Melilotus officinalis had an inhibitory action that was lower than that of hydrocortisone sodium hemisuccinate and similar to coumarin [1]. However, the inner pathway and different features of the exact from Melilotus suaveolens Ledeb for anti-inflammation had never been investigated before.

Generally considering, macrophages play an important role in inflammatory diseases by producing cytokines, such as interleukin-1 beta (IL-1 $\beta$ ), interleukin-6 (IL-6) and tumor necrosis factor-alpha (TNF- $\alpha$ ), and other inflammatory mediators, such as nitric oxide (NO) and prostaglandins. These cytokines and mediators from macrophages have been found in many inflammatory cells and tissues, along with increased expression of their mRNA, following exposure to immune stimulants, including bacterial endotoxin lipopolysaccharide (LPS). Those pro-inflammatory cytokines and mediators are regulated by nuclear factors, 
such as nuclear factor-kappaB (NF-кB). Meanwhile, when pro-inflammatory mediators are released, antiinflammatory cytokines and enzymes, such as interleukin-10 (IL-10) and heme oxygenase-1 (HO-1) are activated and secreted. Activation of pro-inflammatory and anti-inflammatory cytokines and mediators is the key procedure of inflammatory reaction and leads consequent inflammatory impairment and restoration. In experimental practice, RAW 264.7 mouse macrophage cell line stimulated by LPS is widely used as the inflammatory cellular model to study the effect of anti-inflammatory drugs and herbs [2].

In this study, we chose that inflammation cellular model to explore the anti-inflammatory effect, comparing with Dexamethasone, of petroleum ether extract from Melilotus suaveolens Ledeb, and explored the inner anti-inflammatory mechanisms of that medicinal plant.

\section{MATERIALS AND METHODS}

\section{Chemicals and Reagents}

RPMI1640 was from Gibico (Grand Island, NY). Lipopolysaccharide (LPS; Escherichia coli O111:B4) and methyl thiazolyl tetrazolium (MTT) were obtained from Sigma (St. Louis, MO). Affinity-purified goat antimouse HO-1 antibody was obtained from R\&D Systems (Minneapolis, MN). Affinity-purified goat anti-mouse COX-2 antibody and rabbit anti-mouse NF-kB p65 IgG antibody were gotten from Santa Cruz Biotechnology (Santa Cruz, CA). Mouse TNF- $\alpha$, IL-1 $\beta$ and IL-6 ELISA kits were purchased from Quantikine, R\&D Systems (Minneapolis, MN). Griess reagent nitric oxide assay kit was from Beyotime Biotech (Jiangsu, People's Republic of China). Mouse IL-10 ELISA kit was obtained from Bender Medsystem (Vienna, Austria). Trizol was purchased from Gibico (Grand Island, NY). M-MLV Reverse Transcriptase was afforded from Promega (Madison, WI). SYBR Green ${ }^{\circ} \mathrm{C}$ was taken from Biotium (Hayward, CA). The Oligo(dT18) and primers was synthesized by Shanghai Invitrogen (Shanghai, China). The dNTP was obtained from Promega (Madison, WI).

\section{Plant Materials}

Melilotus suaveolens Ledeb was collected in August, 2006 from Long County, Shanxi Province, China and identified by Prof. Ke-Li Chen (School of Pharmacy, Hubei College of Traditional Chinese Med- icine). The raw material plants were stored in the plant specimen department, school of pharmacy, Hubei College of Traditional Chinese Medicine.

\section{Preparation of Petroleum Ether Extract from Melilotus suaveolens Ledeb}

Fifty grams of air-dried Melilotus suaveolens Ledeb were powdered and extracted by $70 \%$ ethanol for three times at $85^{\circ} \mathrm{C}(3 \times 500 \mathrm{ml}, 1.5 \mathrm{~h}$ each $)$. The extract solution was filtered, combined and concentrated in vacuo. Subsequently the concentrated solution was diluted by deionized water to the concentration of $1 \mathrm{~g}$ medicinal substances per $1 \mathrm{ml}$ water. Then $5 \mathrm{ml}$ concentrated liquid was accurately taken into a $100 \mathrm{ml}$ separatory funnel by a $5 \mathrm{ml}$ Mohr measuring pipette and successively extracted with petroleum oil (60-90) to total dry weight of petroleum ether subfraction of $0.425 \mathrm{~g}$. The dry material of petroleum ether subfraction was resuspended with deionized water to a concentration of 75 $\mathrm{mg} / \mathrm{ml}$ for HPLC analysis. Then the solution was diluted by 1640 medium into concentration of 10,5 and $1 \mu \mathrm{g} / \mathrm{ml}$ for interfering in inflammation cellular model.

\section{Cell Culture}

Murine macrophage cell line RAW264.7 was from China Center for Typical Culture Collection (CCTCC; Wuhan, China). The cells were maintained in RPMI1640 medium supplemented with $100 \mathrm{U} / \mathrm{ml}$ of penicillin, 100 $\mu \mathrm{g} / \mathrm{ml}$ of streptomycin and $10 \%$ fetal bovine serum and was cultured at $37^{\circ} \mathrm{C}$ and $5 \% \mathrm{CO}_{2}$ in humidified air.

\section{Cellular Model Establishment and Intervention}

Twenty-four hours prior to LPS treatment, the cells were inoculated into 6,24 or 96 micro-well plates. Twenty-four hours later, when the cells were observed for adherence at the bottom of the well, cell supernatants were disposed and $10 \mathrm{ng} / \mathrm{ml}$ LPS with prepared exact solution were added into the well. The stimulation and intervention lasted for different hours and the supernatants and the cells were harvested for ELISA, real-time PCR, and Western-blot as well as immunocytochemical test.

\section{Control Establishment}

Dexamethasone, which is known as a classic glucocorticosteroid drug widely used in clinical practice, was chosen as positive control with concentration of $0.5 \mu \mathrm{g} / \mathrm{ml}$. Astragalus polysaccharides (APS) is an 
immunomodulator to reinforce immune response in clinic [3]. According to the literature [3], APS with concentration of $100 \mu \mathrm{g} / \mathrm{ml}$ was selected as negative control for monitoring the procedure. Cells stimulated by LPS without any intervention were observed as blank control, whereas cells incubated by 1640 medium were as normal control.

\section{MTT Assay for Measuring Cell Proliferation}

Based on the instruction from the American Type Culture Collection (ATCC), cytotoxic effect of the extract was evaluated by MTT assay. Four hours prior to the culture termination, $20 \mu \mathrm{l}$ MTT solution $(5 \mathrm{mg} / \mathrm{ml}$ in a phosphate-buffered saline, $\mathrm{pH}$ 7.4) was added. When cell culture was terminated, $150 \mu \mathrm{l}$ dimethyl sulfoxide (DMSO) was added into each well for solubilization. The optical density (OD) at $490 \mathrm{~nm}$ was measured by a Spectramax 250 microplate reader.

\section{Cytopathic Effect Test for Cell Morphous Observation}

After cell model interfered with extract for $24 \mathrm{~h}$, cytopathic effect test was performed for observing cell morphous.

\section{Detection of TNF- $\alpha$, IL-1及 and IL-6 in Supernatant}

Inhibitory effects of 10,5 and $1 \mu \mathrm{g} / \mathrm{ml}$ extract on the cytokine TNF- $\alpha$, IL- $1 \beta$ and IL- 6 production from LPStreated RAW264.7 cells were determined by sandwich ELISA. After stimulation and intervention on RAW264.7 cells for $24 \mathrm{~h}$, supernatants were harvested and assayed for TNF- $\alpha$, IL- $1 \beta$ and IL- 6 by respective ELISA kits. The procedure obeyed to instructions from related kits. Results of three independent experiments were used for statistical analysis.

\section{Analysis of Nitric Oxide}

Levels of the nitric oxide (NO) derivative nitrite were determined together with the Griess reaction. The nitrite detection kit was used according to instructions provided by the manufacturer. The samples were assayed in triplicate, and a standard curve using $\mathrm{NaNO}_{2}$ was generated for each experiment for quantification. Briefly, $100 \mu \mathrm{l}$ of medium or standard $\mathrm{NaNO}_{2}$ was mixed with $100 \mu \mathrm{l}$ of Griess reagent in a 96-well plate. After $15 \mathrm{~min}$, optical density was read in a microplate reader at $540 \mathrm{~nm}$.

\section{Real-time PCR for Detecting mRNA of TNF- $\alpha$, COX-2, iNOS and HO-1}

The total RNA from stimulated and interfered cell model was prepared by adding TRIzol Reagent according to manufacturer's protocol. The RNA on TNF- $\alpha$, inducible nitric oxide synthase (iNOS) and cycloxygenase-2 (COX-2) was extracted $4 \mathrm{~h}$ after stimulation and intervention and the RNA on HO-1 was obtained $18 \mathrm{~h}$ after stimulation and intervention. Quantitative PCR was performed in ABI-7700 Sequence Detector (Applied Biosystems, Foster City, CA). The reverse transcription was performed with M-MLV Reverse Transcriptase. The Reverse Transcription reaction system included: 5.5 $\mu \mathrm{l} \mathrm{H}_{2} \mathrm{O}, 1.0 \mu \mathrm{l}$ Oligo(dT18; $\left.50 \mu \mathrm{g} / \mathrm{ml}\right)$, Total RNA 6.0 $\mu \mathrm{l}, 70^{\circ} \mathrm{C} 5 \mathrm{~min}$ to ice for unfolding secondary structure of mRNA; $0.5 \mu \mathrm{l} \mathrm{RNasin}(40 \mathrm{U} / \mu \mathrm{l}), 4.0 \mu \mathrm{l} 5 \times$ buffer, $2.0 \mu \mathrm{ldNTP}(10 \mathrm{mM}), 1.0 \mu \mathrm{l}$ RTase $(200 \mathrm{U} / \mu \mathrm{l}), 42^{\circ} \mathrm{C}$ $60 \mathrm{~min}$ to $95^{\circ} \mathrm{C} 5 \mathrm{~min}$ to $4^{\circ} \mathrm{C}$. Real time PCR reaction was performed with SYBR Green ${ }^{\circ} \mathrm{C}$ fluorochrome. The standard curve of each sample was obtained and cycle threshold $(\mathrm{Ct})$ value was calculated. Each $50 \mu \mathrm{l}$ PCR system contained $1 / 50$ of the original cDNA synthesis reaction, $7 \mu \mathrm{l}(25 \mathrm{mM}) \mathrm{MgCl}_{2}, 0.8 \mu \mathrm{l}(20 \mathrm{pmol} / \mu \mathrm{l})$ of each primer, $1 \mu \mathrm{l}(10 \mathrm{mM}) \mathrm{dNTP}, 1 \mu \mathrm{S} \mathrm{SYBR}$ Green ${ }^{\circ} \mathrm{C}$, $0.5 \mu \mathrm{l}(5 \mathrm{U} / \mu \mathrm{l}) \mathrm{Taq}$ and $5 \mu \mathrm{l} 10 \times$ Buffer. Fifty cycles of amplification were performed: after $94^{\circ} \mathrm{C} 3 \mathrm{~min}$, reaction cycle with $94^{\circ} \mathrm{C}, 30 \mathrm{~s}$, to $57^{\circ} \mathrm{C}, 30 \mathrm{~s}$, then to $72^{\circ} \mathrm{C}, 30 \mathrm{~s}$ was carried out for 50 times. The fluorescence signal was detected at the end of each cycle. Melting curve analysis was used to confirm the specificity of the products. The $2^{-\triangle \Delta C T}$ method was performed to analyze the results [4]. The primer was as below:

\section{-Mus-COX-2:}

Forward: 5'-GAAGTCTTTGGTCTGGTGCCTG-3', Reverse: 5'-GTCTGCTGGTTTGGAATAGTTGC-3'; -Mus-iNos:

Forward: 5'-GGAGCGAGTTGTGGATTGTC-3', Reverse:5'-GTGAGGGCTTGGCTGAGTGAG-3'; -Mus-TNF- $\alpha$ :

Forward: 5'-GTGGAACTGGCAGAAGAGGC-3', Reverse: 5'-AGACAGAAGAGCGTGGTGGC-3'; -Mus-HO-1:

Forward: 5'-CACAGATGGCGTCACTTCGTC-3', Reverse: 5'-GTGAGGACCCACTGGAGGAG-3'. -Mus- $\beta$-actin:

Forward: 5'-GCTACAGCTTCACCACCACAG-3', Reverse: 5'-GGTCTTTACGGATGTCAACGTC-3'. 


\section{Western Blot Analysis of COX-2 and HO-1}

The treated cells were harvested and incubated on ice for $15 \mathrm{~min}$ in a lysis buffer of $50 \mathrm{mM}$ Tris- $\mathrm{HCl}(\mathrm{pH}$ 7.4), $150 \mathrm{mM} \mathrm{NaCl}, 100 \mathrm{mg} / \mathrm{ml}$ phenyl methylsulfonyl fluoride, $1 \mathrm{mg} / \mathrm{ml}$ aprotinin, and $1 \%$ Triton X-100. Cell debris was removed by centrifugation at $10,000 \mathrm{rpm}$ and $4{ }^{\circ} \mathrm{C}$ for $10 \mathrm{~min}$ The protein concentration of each cell lysate was determined together with a Bio-Rad (Hercules, CA, USA) protein assay kit. To each tube, an equivalent volume of $2 \times$ sodium dodecyl sulfate (SDS) loading buffer (100 mM Tris-HCl,pH 6.8, 4\% SDS, $20 \%$ glycerine, $10 \% b$-mercaptoethanol, and $0.2 \%$ bromophenol blue) was added and mixed again. The mixtures were then denatured at $95^{\circ} \mathrm{C}$ for $10 \mathrm{~min}$, and about $10 \mathrm{mg}$ of the protein mixture was loaded and separated in each well on $10 \%$ SDS-polyacrylamide electrophoresis gels. After separation for about $80 \mathrm{~min}$, the proteins were transblotted onto nitrocellulose membranes (Bio-Rad), and the membranes were saturated and blocked with $5 \%$ fat-free milk at $37^{\circ} \mathrm{C}$ for $1 \mathrm{~h}$. Membranes were probed with goat polyclonal anti-COX-2, anti-HO-1 (1:6000) and then with horseradish peroxidase-conjugated secondary immunoglobulin G (IgG, Kangcheng, Shanghai, People's Republic of China). The membranes were then treated with an enhanced chemiluminescence reagent (Amersham, Piscataway, NJ), and the signals were detected by exposure of the membranes to X-ray films (Kodak, Rochester, NY, USA). The relative signal intensity was quantified by densitometry with Gel pro3.0 image software (Media Cybernetics, Silverspring, MD, USA) on an IBM-compatible personal computer. All experiments were independently performed three times.

\section{Immunocytochemistry Assay on NF-кB}

SP immunocytochemical assay was employed to detect expression of the nuclear translocation of NF- $\mathrm{\kappa B}$.
Coverslips were soaked in polylysine for a whole night. After cell crawling to the coverslips and subsequent LPS stimulation and extract intervention, the cells were fixed by acetone. Then the slides with cells were soaked in $3 \%$ $\mathrm{H}_{2} \mathrm{O}_{2}$-methanol solution for $20 \mathrm{~min}$ in order to block endogenous peroxydase. Next $1 \%$ Triton X-100 was added at $37^{\circ} \mathrm{C}$ for $5 \mathrm{~min}$, followed by PBS washing. After incubated with normal goat serum at room temperature for $20 \mathrm{~min}$, rabbit anti-mouse NF-кB p65 IgG antibody was dropwised and the slides were stored at $4^{\circ} \mathrm{C}$ for a whole night. Next day following PBS washing, biotin-conjugated goat anti rabbit IgG was dropwised and the incubation lasted $30 \mathrm{~min}$ at $37^{\circ} \mathrm{C}$. Then with PBS wash again, streptavidin-HRP was added and incubated with cells for $30 \mathrm{~min}$ at $37^{\circ} \mathrm{C}$. Subsequently with PBS washing for $5 \mathrm{~min}$, three times, DAB coloration was performed. Following normal dehydration, lucidification and mounting, the slides were pictured.

\section{HPLC Fingerprint for Analyzing the Herb Extract}

High performance liquid chromatography (HPLC) fingerprint was used to analyze the ingredients of the herb extract [5]. Balance (AB204-N, MAX $210 \mathrm{~g}$, $d=0.1 \mathrm{mg}$, produced by MERRLER TOLEDO Group) and UV-Detector (8450/HP, Agilent Science of Life and Chemistry Company) were used. The HPLC system consisted of a pump (model DIONEX P680 HPLC Pump, ASI-100 to form a high pressure gradient) with Automated Sample Injector facility, Chromeleon management system and UV-VIS (UVD 170U) model detector. The column was Kromasil C-18 $(250 \times 4.6$ $\mathrm{mm}, 10 \mathrm{~nm}-5 \mu \mathrm{m}$, Hanbon Science \&.Technology Co., Ltd). Chromatography conditions included: the gradient elution was acetonitrile and $0.05 \% \mathrm{H}_{3} \mathrm{PO}_{4}$ of $1.0 \mathrm{ml} / \mathrm{min}$ flowing rate; $5 \mu$ capacity per injection was used with UV detector at four kinds of wavelength of $220 \mathrm{~nm}$ (for coumarin), $254 \pm 2 \mathrm{~nm}, 275 \mathrm{~nm}$ (for coumarin and rutin)
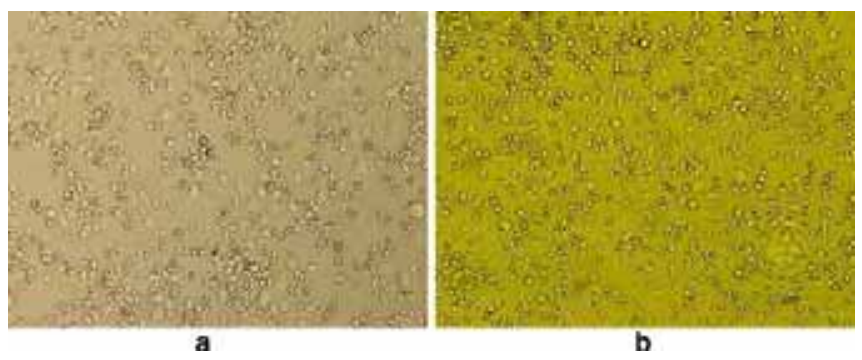

Fig. 1. a The RAW 264.7 cells before intervention of petroleum ether extract from Melilotus suaveolens Ledeb; b the cells after intervention of 10 $\mu \mathrm{g} / \mathrm{ml}$ petroleum ether extract from Melilotus suaveolens Ledeb. 
and $363 \mathrm{~nm}$ (for hyperoside); the concentration of reference of coumarin, rutin and hyperoside was $0.007648,0.2548$ and $0.2528 \mathrm{mg} / \mathrm{ml}$, respectively; the column was placed in a column oven set at $25^{\circ} \mathrm{C}$. Then the petroleum ether subfraction was filtered through a $0.45 \mu \mathrm{m}$ filter membrane (Hanbon Science \&.Technology Co., Ltd) and stored in the refrigerator before use. The multi-step gradient elution was carried out with acetonitrile and $0.05 \% \mathrm{H}_{3} \mathrm{PO}_{4}$ solution. The procedure was as follows: $0-8 \mathrm{~min}\left(5 \%\right.$ acetonitrile, $95 \% \mathrm{H}_{3} \mathrm{PO}_{4}$ solution), $8-25 \min (5 \%$ acetonitrile $-30 \%$ acetonitrile, $95 \% \mathrm{H}_{3} \mathrm{PO}_{4}$ solution $-70 \% \mathrm{H}_{3} \mathrm{PO}_{4}$ solution), 25-35 min $\left(30 \%\right.$ acetonitrile, $70 \% \mathrm{H}_{3} \mathrm{PO}_{4}$ solution), 35-60 $\min \left(30 \%\right.$ acetonitrile $-70 \%$ acetonitrile, $70 \% \mathrm{H}_{3} \mathrm{PO}_{4}$ solution $-30 \% \quad \mathrm{H}_{3} \mathrm{PO}_{4}$ solution), $60-70 \mathrm{~min}(30 \%$ acetonitrile $-5 \%$ acetonitrile, $70-95 \% \mathrm{H}_{3} \mathrm{PO}_{4}$ solution), $70-80 \mathrm{~min}$ (5\% acetonitrile, $95 \% \mathrm{H}_{3} \mathrm{PO}_{4}$ solution).

\section{Statistical Analysis}

Data were presented as means \pm SD of three separate experiments. Comparisons between multiple groups were performed with one-way ANOVA test. Statistical significance was considered significant when $p<0.05$.

\section{RESULTS}

\section{In vitro Cytotoxicity of Petroleum Ether Extract from Melilotus suaveolens Ledeb}

Based on MTT assay, it showed that pretreatment on unstimulated RAW264.7cells lines with prepared solution from petroleum ether extract from Melilotus suaveolens Ledeb (concentration mentioned above) for

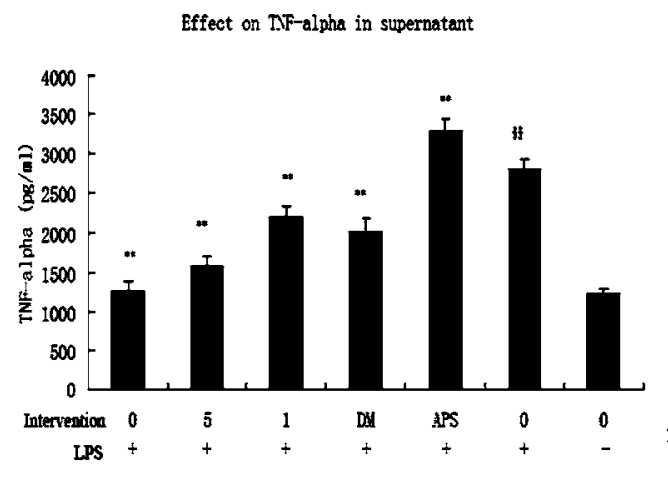

a

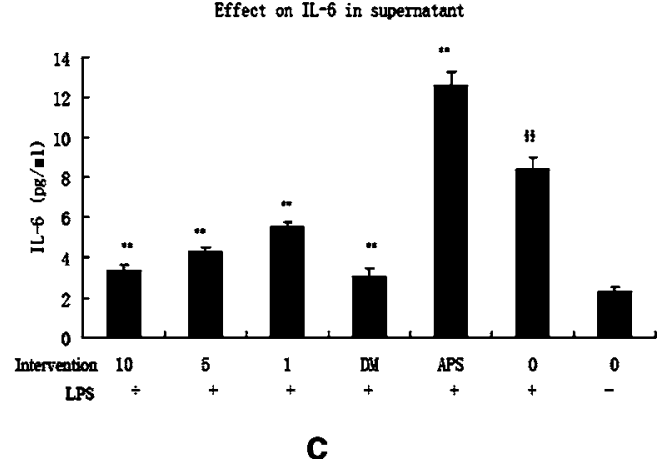

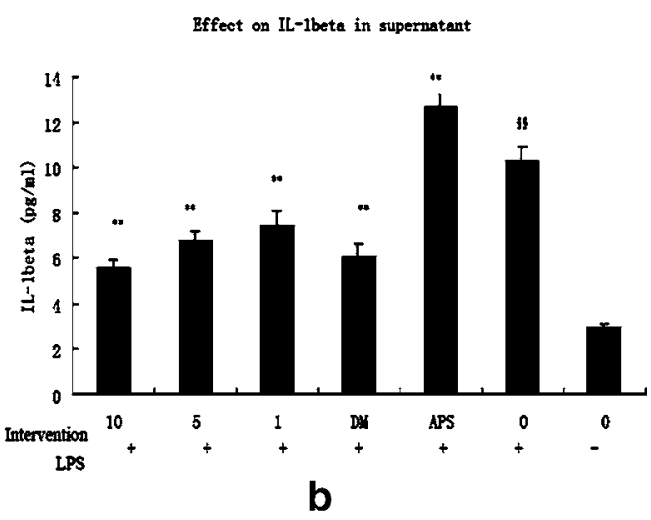

Effect on $: 0$ in supernatant

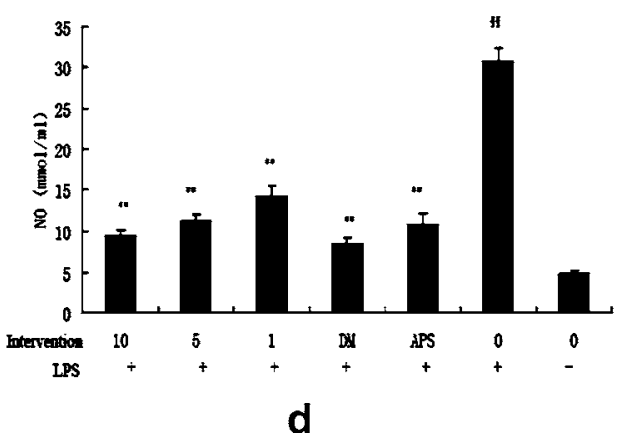

Fig. 2. Effects of petroleum ether extract from Melilotus suaveolens Ledeb on pro-inflammatory cytokines and mediators production. RAW264.7 cells were treated with LPS $(10 \mathrm{ng} / \mathrm{ml})$ in the presence of different concentrations of petroleum ether extract from Melilotus suaveolens Ledeb for $24 \mathrm{~h}$. Cytokine or mediator levels were measured by ELISA or Griess method. Data were shown as mean $\pm \mathrm{SD}(n=3)$. Single asterisks, $p<0.05$ compared to LPS alone; double asterisks, $p<0.01$ compared to LPS alone; single section marks, $p<0.05$ compared to normal cell; double section marks, $p<0.01$ compared to normal cell. a effect on TNF- $\alpha$ production; $\mathbf{b}$ effect on IL- $1 \beta$ production; $\mathbf{c}$ effect on IL-6 production; d effect on NO production. 
$24 \mathrm{~h}$ did not significantly affect cell viability (data not shown). Cytopathic effect (CPE) test presented the same result (Fig. 1).

\section{Inflammatory Model Establishment and Procedure Monitoring}

As shown from figures on pro-inflammatory cytokines and mediators, the levels from cells stimulated by LPS were significantly higher than those of normal cells $(p<0.01)$, which implied the successful establishment on model of inflammation. Meanwhile, the levels of those mediators from cells by Dexamethasone intervention was significantly lower than those from single LPS stimulation $(p<0.01)$. The levels of those mediators from cells by APS intervention, an immunomodulator for enhancing immune response, was significantly higher than those from single LPS stimu- lation ( $p<0.05$ or 0.01$)$. The effects of Dexamethasone and APS intervention demonstrated experimental procedure was proper.

\section{Effect of Petroleum Ether Extract from Melilotus suaveolens Ledeb on Pro-inflammatory Cytokines Stimulated by LPS}

As shown in Fig. 2a-c, after LPS stimulation with the extract intervention for $24 \mathrm{~h}$, secretion of TNF- $\alpha$, IL-1 $\beta$ and IL- 6 were significantly decreased than that in single LPS stimulation $(p<0.01)$. Furthermore, the more increasing on dosage of the extract, the better effects of antagonizing pro-inflammatory cytokines $(p<0.05$ except IL-1 $\beta$ ), which showed dose-dependent relation between anti-inflammatory effect and petroleum ether extract from Melilotus suaveolens Ledeb.
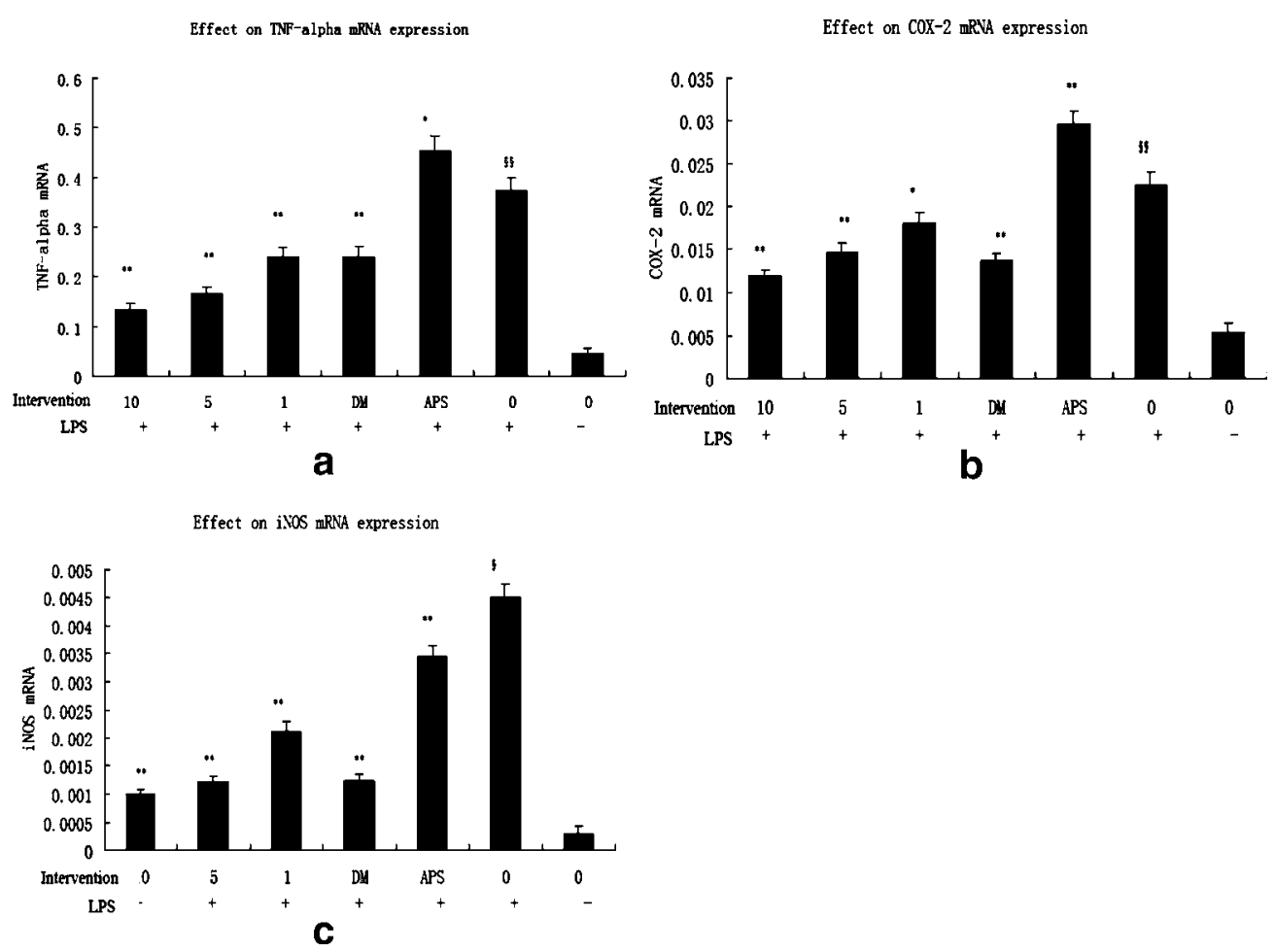

Fig. 3. Effects of petroleum ether extract from Melilotus suaveolens Ledeb on pro-inflammatory cytokines and mediators mRNA expression. RAW264.7 cells were treated with LPS $(10 \mathrm{ng} / \mathrm{ml})$ in the presence of different concentrations of petroleum ether extract from Melilotus suaveolens Ledeb for $4 \mathrm{~h}$. Cytokine or mediator mRNA levels were measured by Real-time PCR. Data were shown as mean $\pm \mathrm{SD}(n=3)$. Single asterisks, $p<0.05 \mathrm{com}-$ pared to LPS alone; double asterisks, $p<0.01$ compared to LPS alone; single section marks, $p<0.05$ compared to normal cell; double section marks, $p<0.01$ compared to normal cell. a effect on TNF- $\alpha$ mRNA expression; b effect on COX-2 mRNA expression; $\mathbf{c}$ effect on iNOS mRNA expression. 

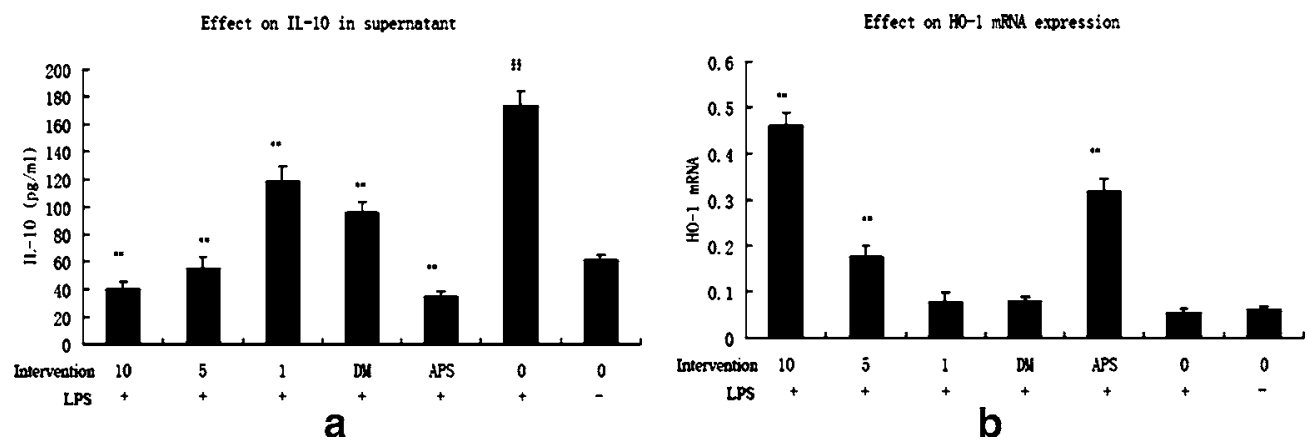

Fig. 4. Effects of petroleum ether extract from Melilotus suaveolens Ledeb on anti-inflammatory cytokines and mediators expression. RAW264.7 cells were treated with LPS $(10 \mathrm{ng} / \mathrm{ml})$ in the presence of different concentrations of petroleum ether extract from Melilotus suaveolens Ledeb for $24 \mathrm{~h}$ (IL-10) or $18 \mathrm{~h}$ (HO-1 mRNA). The IL-10 levels were measured by ELISA and HO-1 mRNA levels were measured by Real-time PCR. Data were shown as mean $\pm \mathrm{SD}(n=3)$. Single asterisks, $p<0.05$ compared to LPS alone; double asterisks, $p<0.01$ compared to LPS alone; single section marks, $p<0.05$ compared to normal cell; double section marks, $p<0.01$ compared to normal cell. a effect on IL-10 production; b effect on HO-1 mRNA expression.

\section{Effect of Petroleum Ether Extract from Melilotus suaveolens Ledeb on Protein of COX-2 Stimulated by LPS}

The extract displayed strikingly decreased level of COX-2 protein as shown in Fig. 5 by the method of Western blot analysis $(p<0.01)$. It is suggested that petroleum ether extract from Melilotus suaveolens Ledeb could control pro-inflammatory cytokine production at protein levels.

\section{Effect of Petroleum Ether Extract from Melilotus suaveolens Ledeb on mRNA of Pro-inflammatory Mediators Stimulated by LPS}

The extract displayed strikingly decreased level of TNF- $\alpha$ and COX-2 mRNA as shown in Fig. 3a-b $(p<0.01$ or 0.05$)$. It is suggested that petroleum ether extract from Melilotus suaveolens Ledeb may control pro-inflammatory cytokine production at gene levels.
Furthermore, the more increasing on dosage of the extract, the better effects of antagonizing pro-inflammatory gene expression $(p<0.05)$, which showed dosedependent relation between controlling effect on inflammatory gene and petroleum ether extract from Melilotus suaveolens Ledeb.

\section{Effect of Petroleum Ether Extract from Melilotus suaveolens Ledeb on NO and iNOS Stimulated by LPS}

As shown in Fig. 2d, after LPS stimulation with petroleum ether extract from Melilotus suaveolens Ledeb intervention, secretion of nitric oxide (NO) was significantly decreased than that in single LPS stimulation $(p<0.01)$. Furthermore, the more increasing on dosage of petroleum ether extract from Melilotus suaveolens Ledeb, the better effects of antagonizing NO releasing, which showed dose-dependent relation

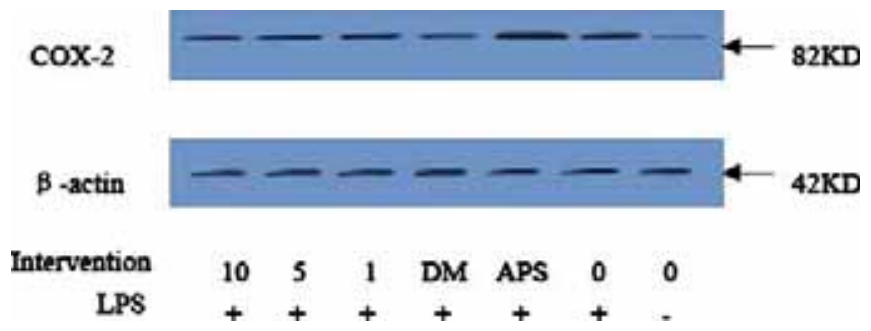

Fig. 5. Effects of petroleum ether extract from Melilotus suaveolens Ledeb on COX-2 protein expression assayed by Western blot analysis. RAW264.7 cells were treated with LPS $(10 \mathrm{ng} / \mathrm{ml})$ in the presence of different concentrations of petroleum ether extract from Melilotus suaveolens Ledeb for $24 \mathrm{~h}$. 
on the extract. As shown from Fig. 3c, effect of petroleum ether extract from Melilotus suaveolens Ledeb on mRNA expression of iNOS was coincidence with that on NO $(p<0.01)$.

\section{Effect of Petroleum Ether Extract from Melilotus suaveolens Ledeb on IL-10 Stimulated by LPS}

As shown in Fig. 4a, the level of IL-10 was decreased the most under APS condition, which illustrated the effect of APS on reinforcing cellular immunity and inhibiting humoral immunity. Increase of IL-10 on single LPS stimulation displayed the regulatory action on cells after inflammatory reaction. The levels of IL-10 on the extracts intervention were similar to that on Dexamethasone intervention (Fig. 5).

\section{Effect of Petroleum Ether Extract from Melilotus suaveolens Ledeb on HO-1 mRNA and Protein Expression Stimulated by LPS}

As shown in Figs. 4b and 6, the levels of HO-1 mRNA and protein on single LPS stimulated cells and Dexamethasone interfered cells were not different to the level on normal incubated cell. The levels of HO-1 mRNA and protein on $10 \mu \mathrm{g} / \mathrm{ml}$ and $5 \mu \mathrm{g} / \mathrm{ml}$ Melilotus suaveolens Ledeb and APS intervention were significantly higher than those on single LPS stimulation and normal incubation $(p<0.01)$, which suggested that petroleum ether extract from Melilotus suaveolens Ledeb could promote regression of inflammatory. Furthermore, the higher concentration of Melilotus suaveolens Ledeb, the stronger expression of HO-1 mRNA and protein $(p<0.01)$, which showed dose-dependent relation between promoting anti-inflammatory mediators effect and petroleum ether extract from Melilotus suaveolens Ledeb.

\section{Inhibition Effect of NF-kB on Petroleum Ether Extract from Melilotus suaveolens Ledeb}

The results of immunocytochemistry in Fig. 7 showed NF- $\mathrm{KB}$ activation was significantly blocked by petroleum ether extract from Melilotus suaveolens Ledeb $(p<0.01)$. Those results suggested that suppression of IL$1 \beta$, TNF- $\alpha$, iNOS, and COX-2 expression by petroleum ether extract from Melilotus suaveolens Ledeb might be due to the attenuation of NF- $\kappa \mathrm{B}$ activation.

\section{HPLC Fingerprint of Petroleum Ether Extract from Melilotus suaveolens Ledeb}

From the HPLC fingerprint analysis as shown in Fig. 8, no peaks coincided between the extract and the other standard substances but coumarin under detection of each wavelength. Thereby, could inferred coumarin be the only ingredient in the extract. According to the peak height and the content of standard coumarin, the concentration of coumarin in each $10 \mathrm{~g}$ extract was calculated as $0.27822 \mathrm{mg}$.

\section{DISCUSSION}

It was documented that the Melilotus species (including sweet clover) had been used to reduce spasm [6]. Its coumarinic extract was confirmed to have effect on lymphedema [7] and its polysaccharides had immunocorrecting, antianemia and adaptogenic effects [8]. However the anti-inflammatory effect on Melilotus suaveolens Ledeb had not been reported and related exploration on molecular biological mechanism of that plant on how to play an anti-inflammatory role remained limited.

As discovered now, NF- $\kappa \mathrm{B}$ is a family of seven structurally related transcription factors that play a

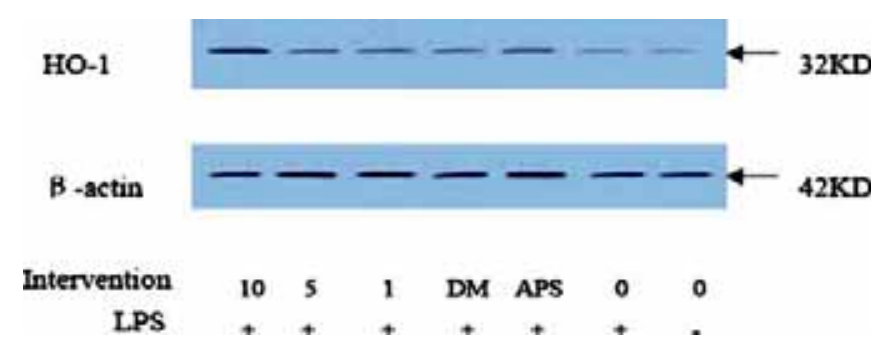

Fig. 6. Effects of petroleum ether extract from Melilotus suaveolens Ledeb on HO-1 protein expression assayed by Western blot analysis. RAW264.7 cells were treated with LPS $(10 \mathrm{ng} / \mathrm{ml})$ in the presence of different concentrations of petroleum ether extract from Melilotus suaveolens Ledeb for $24 \mathrm{~h}$. 


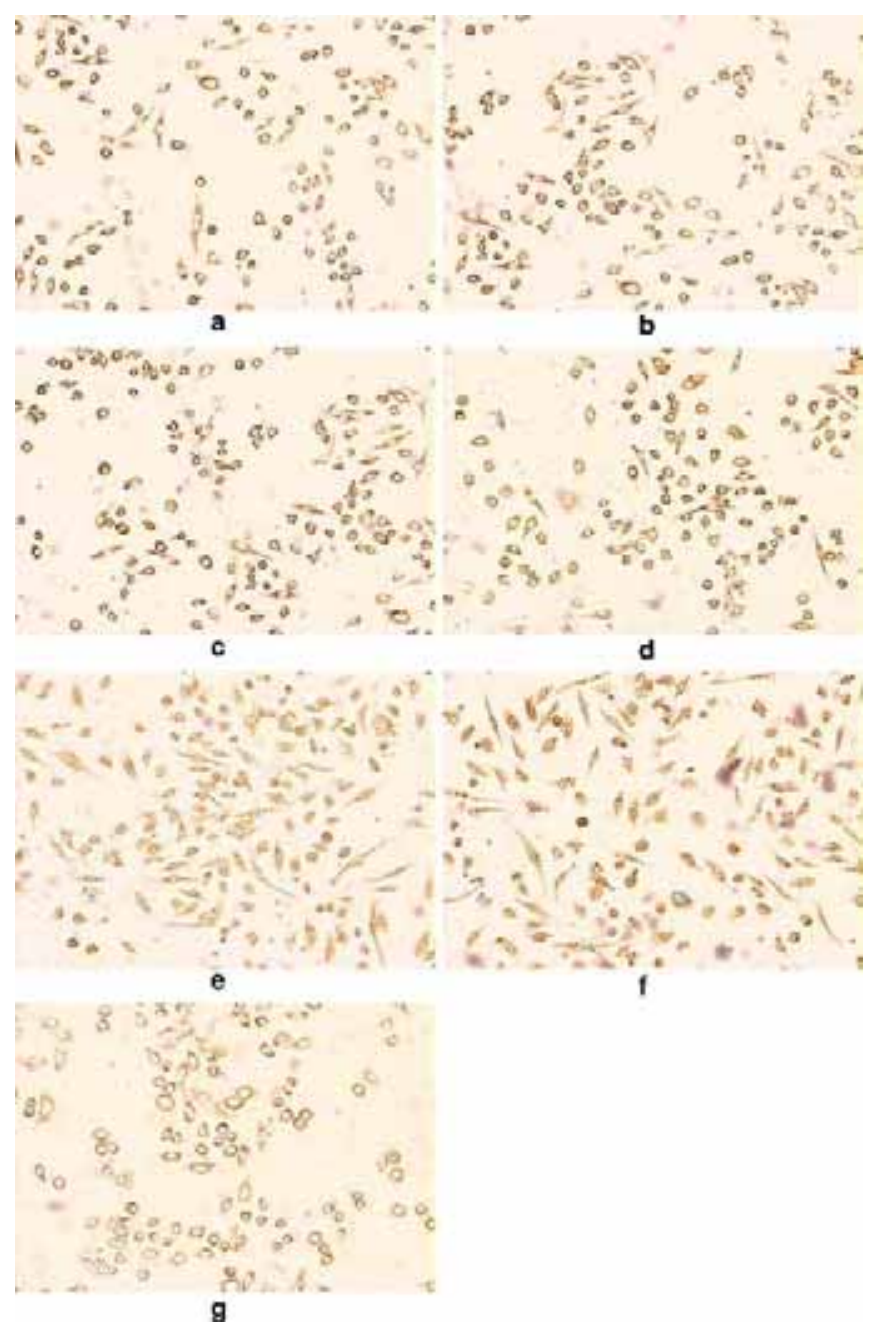

Fig. 7. Effects of petroleum ether extract from Melilotus suaveolens Ledeb on NF- $\kappa$ B translocation. RAW264.7 cells were treated with LPS (10 ng/ml) in the presence of different concentrations of the extract for $2 \mathrm{~h}$. Cell nucleus stained to brown presented NF- $\mathrm{KB}$ activation and cytoplasm stained to brown presented NF- $\kappa \mathrm{B}$ inactivation. a $10 \mu \mathrm{g} / \mathrm{ml}$ extract plus LPS; b $5 \mu \mathrm{g} / \mathrm{ml}$ extract plus LPS; c $1 \mu \mathrm{g} / \mathrm{ml}$ extract plus LPS; d Dexamethasone plus LPS; e APS plus LPS; f simple LPS; g normal medium.

central role in inflammation by controlling gene network expression [9]. Cyclooxygenease-2 (COX-2) is the key enzyme regulating the production of prostaglandins, and the central mediators of inflammation. The expression of cyclooxygenease- 2 is induced by several extra cellular signals including pro-inflammatory stimuli. Cyclooxygenease- 2 can be affected directly at its enzymatic activity by nitric oxide and inducible nitric oxide synthase (iNOS) [10]. Nitric oxide (NO) is recognized as a mediator and regulator of inflammatory responses. It possesses cytotoxic properties that are aimed against pathogenic microbes, but it can also have damaging effects on host tissues. The effect of NO has a significant role in inflammation, where NO is produced in high amounts by inducible nitric oxide synthase (iNOS) and reactive oxygen species are synthesized by activated inflammatory cells [11]. Several pro-inflammatory gene products have been identified that mediate a critical role in inflammation. Among these gene products are TNF and members of its superfamily, IL-1 $\beta$, IL- 6 , etc. The 


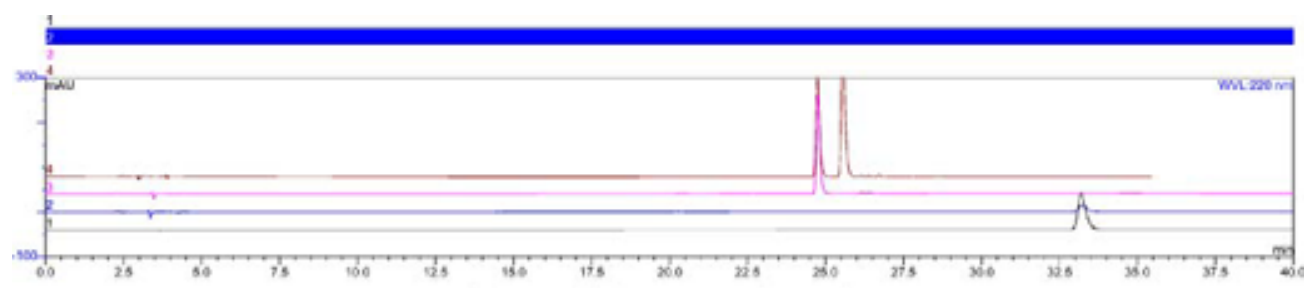

$8-1$ : at $220 \mathrm{~nm}$ wavelength

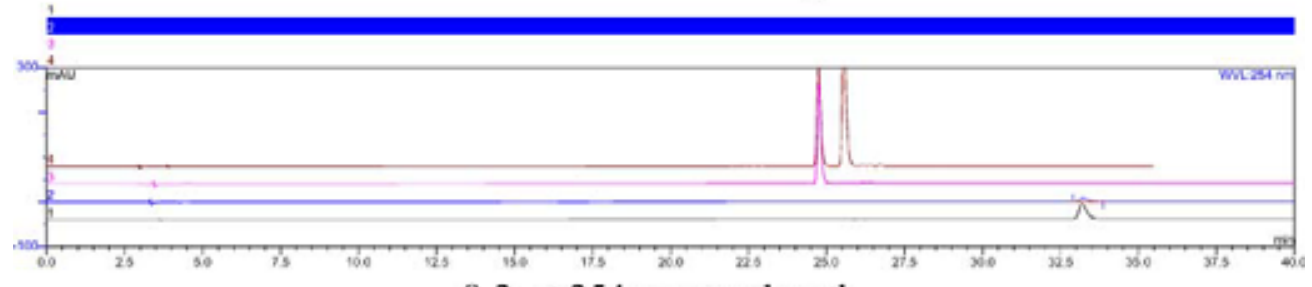

$8-2$ : at $254 \mathrm{~nm}$ wavelength

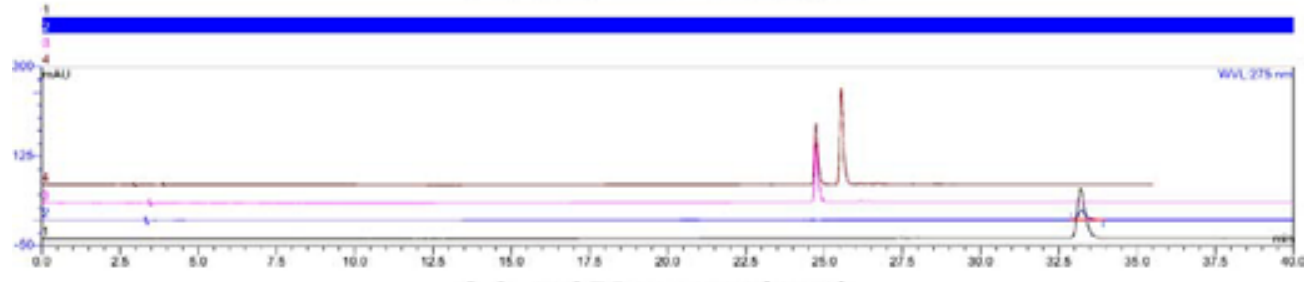

$8-3$ : at $275 \mathrm{~nm}$ wavelength

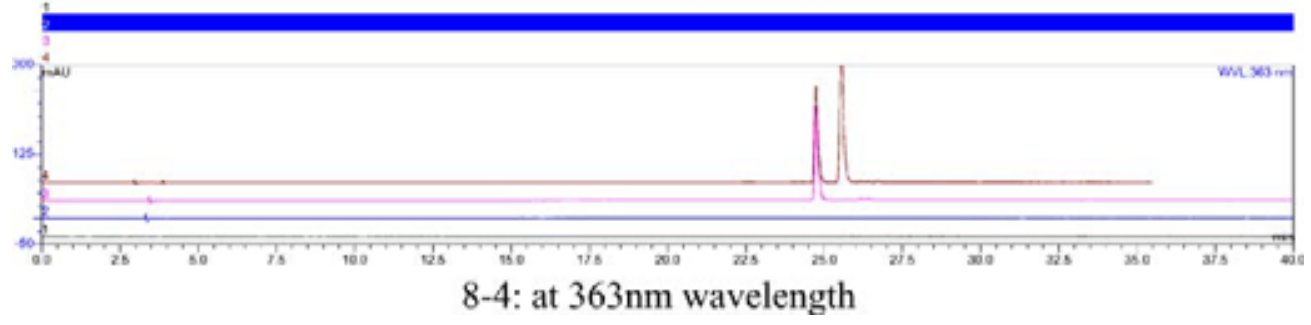

Fig. 8. HPLC fingerprint analysis of the petroleum ether extract. Brown line represents standard rutin and hyperoside solution; red line represents standard rutin solution; blue line represents standard substances of coumarin; black line represents petroleum ether extract. 14-1: at $220 \mathrm{~nm}$ wavelength; 14-2: at $254 \mathrm{~nm}$ wavelength; 14-3: at 275 nm wavelength; 14-4: at $363 \mathrm{~nm}$ wavelength.

expression of all these genes is mainly regulated by the transcription factor NF-kappaB [12]. Therefore, whether suppressing those pro-inflammatory cytokines and mediators is a key to evaluate anti-inflammatory drugs.

IL-10 has attached much attention because of its antiinflammatory properties. Uniquely among haematopoietic cytokines, IL-10 is a pleiotropic molecule that displays both immunostimulatory and immunoregulatory activities [13]. HO-1, involved in the heme degradation process, is an important anti-inflammatory enzyme featured by its antioxidant activity [14]. Experimental models of various diseases, including acute inflammation, have demonstrat- ed that the induction of HO-1 can prevent or mitigate the symptoms associated with these ailments [15].

In our research, we first examined the differences between simple LPS stimulation and normal culture, between Dexamethasone intervention and simple LPS stimulation, and between APS intervention and simple LPS stimulation. The results implied the successful establishment of inflammation model and the experimental procedure was proper.

Subsequently, we examined the effect of petroleum ether extract from Melilotus suaveolens Ledeb and found that it could influence the cytokines and media- 
tors in pro-inflammatory and anti-inflammatory pathway at gene and protein levels, including TNF- $\alpha$, IL-1 $\beta$, IL-6, NO, COX-2, HO-1. Furthermore, the effect showed a dose-dependent relation on the extract, which illustrated the anti-inflammatory properties of that extract. The suppressive effect on inflammatory initial transcriptional factor NF- $\mathrm{BB}$ demonstrated the inner antiinflammatory mechanisms of petroleum ether extract from Melilotus suaveolens Ledeb. In addition, we compared the anti-inflammatory effect between petroleum ether extract from Melilotus suaveolens Ledeb and Dexamethasone, and it could be observed that petroleum ether extract from Melilotus suaveolens Ledeb had the similar efficacy on antagonizing the producing and releasing of proinflammatory mediators, cytokines and NF- $\kappa \mathrm{B}$.

On the other hand, at the aspect of promoting antiinflammatory cytokines and mediators, Dexamethasone can inhibit the release of IL-10 at high dosage [16], while we found petroleum ether extract from Melilotus suaveolens Ledeb had a similar effect on IL-1. However, petroleum ether extract from Melilotus suaveolens Ledeb, not Dexamethasone, had ability on inducing production of HO-1, which showed a difference on this antiinflammatory mediator. This feature might be a possible application of Melilotus suaveolens Ledeb in clinical practice in the future.

HPLC fingerprint of the herb extract showed that the only content of petroleum ether extract from Melilotus suaveolens Ledeb was coumarin. Although more than 1300 coumarins have been identified from natural sources [17], and various pharmacological and biochemical actions were identified in the past [18], the coumarin in Melilotus suaveolens Ledeb has not been well investigated. The effect of coumarin in Melilotus suaveolens Ledeb on pro-inflammatory cytokines and mediators, on blocking translocation of NF-kappaB, on anti-inflammatory mediators and on comparison to Dexamethasone are first explored in our research. The next exploration is on further analysis of coumarin from Melilotus suaveolens Ledeb and application of this medicinal plant product on certain inflammation-related disease.

\section{REFERENCES}

1. Plesca-Manea, L., A. E. Parvu, M. Parvu, M. Taamas, R. Buia, and M. Puia. 2002. Effects of Melilotus officinalis on acute inflammation. Phytother. Res. 16:316-319.
2. Kim, K. M., Y. G. Kwon, H. T. Chung, Y. G. Yun, H. O. Pae, J. A. Han, K. S. Ha, T. W. Kim, and Y. M. Kim. 2003. Methanol extract of Cordyceps pruinosa inhibits in vitro and in vivo inflammatory mediators by suppressing NF-kappaB activation. Toxicol. Appl. Pharmacol. 190:1-8.

3. Shao, B. M., W. Xu, H. Dai, P. Tu, Z. Li, and X. M. Gao. 2004. A study on the immune receptors for polysaccharides from the roots of Astragalus membranaceus, a Chinese medicinal herb. Biochem. Biophys. Res. Commun. 320:1103-1111.

4. Livak, K. J., and T. D. Schmittgen. 2001. Analysis of relative gene expression data using real-time quantitative PCR and the 2(-Delta Delta C(T)) Method. Methods 25:402-408.

5. Qi, L. W., Q. T. Yu, P. Li, S. L. Li, Y. X. Wang, L. H. Sheng, and L. Yi. 2006. Quality evaluation of Radix Astragali through a simultaneous determination of six major active isoflavonoids and four main saponins by high-performance liquid chromatography coupled with diode array and evaporative light scattering detectors. J. Chromatogr. A 1134:162-169.

6. Zoltan, O. T., and M. Foldi. 1970. Effect of coumarin from Melilotus officinalis on the convulsion threshold of the central nervous system in rats and guinea pigs. Arzneim.-Forsch. 20:1625.

7. Pastura, G., M. Mesiti, M. Saitta, D. Romeo, N. Settineri, R. Maisano, M. Petix, and A. Giudice. 1999. Lymphedema of the upper extremity in patients operated for carcinoma of the breast: clinical experience with coumarinic extract from Melilotus officinalis. Clin. Ter. 150:403-408.

8. Podkolzin, A. A., V. I. Dontsov, I. A. Sychev, G. YU. Kobeleva, and O. N. Kharchenko. 1996. Immunocorrecting, antianemia, and adaptogenic effects of polysaccharides from Melilotus officinalis. Biull. Eksp. Biol. Med. 121:661-663.

9. Brasier, A. R. 2006. The NF-kappaB regulatory network. Cardiovasc. Toxicol. 6:111-130.

10. Tsatsanis, C., A. Androulidaki, M. Venihaki, and A. N. Margioris. 2006. Signalling networks regulating cyclooxygenase-2. Int. J. Biochem. Cell. Biol. 38:1654-1661.

11. Korhonen, R., A. Lahti, H. Kankaanranta, and E. Moilanen. 2005. Nitric oxide production and signaling in inflammation. Curr. Drug Targets Inflamm. Allergy 4:471-479.

12. Aggarwal, B. B., S. Shishodia, S. K. Sandur, M. K. Pandey, and G. Sethi. 2006. Inflammation and cancer: how hot is the link? Biochem. Pharmacol. 72:1605-1621.

13. Harizi, H., and N. Gualde. 2006. Pivotal role of PGE2 and IL-10 in the cross-regulation of dendritic cell-derived inflammatory mediators. Cell. Mol. Immunol. 3:271-277.

14. Abraham, N. G., A. Asija, G. Drummond, and S. Peterson. 2007. Heme oxygenase-1 gene therapy: recent advances and therapeutic applications. Curr Gene Ther. 7:89-108.

15. Prawan, A., J. K. Kundu, and Y. J. Surh. 2005. Molecular basis of heme oxygenase-1 induction: implications for chemoprevention and chemoprotection. Antioxid. Redox Signal. 7:1688-1703.

16. Franchimont, D., H. Martens, M. T. Hagelstein, E. Louis, W. Dewe, G. P. Chrousos, J. Belaiche, and V. Geenen. 1999. Tumor necrosis factor alpha decreases, and interleukin-10 increases, the sensitivity of human monocytes to dexamethasone: potential regulation of the glucocorticoid receptor. J. Clin. Endocrinol. Metab. 84:2834-2839.

17. Hoult, J. R., and M. Paya. 1996. Pharmacological and biochemical actions of simple coumarins: natural products with therapeutic potential. Gen. Pharmacol. 27:713-722.

18. Fylaktakidou, K. C., D. J. Hadjipavlou-Litina, K. E. Litinas, and D. N. Nicolaides. 2004. Natural and synthetic coumarin derivatives with anti-inflammatory/ antioxidant activities. Curr. Pharm. Des. 10:3813-3833. 